\title{
AVALIAÇÃO DA CORRELAÇÃO ENTRE PRESENÇA DE PRAGAS E PREVALÊNCIA DE SALMONELLA EM FÁBRICA DE FARINHA DE PEIXE ${ }^{1}$
}

\author{
José Humberto de Souza \\ Nicoluzzi RAÇÕES LTDA, e-mail: gerenciatecnica@nicoluzzi.com.br \\ Simone Moraes Raszl \\ SENAI/SC, e-mail: simone@sc.senai.br
}

\begin{abstract}
RESUMO: Ingredientes de origem animal, como a farinha de peixe, são importantes fontes de proteína para alimentos para animais. A presença de patógenos zoonóticos, como a Salmonella spp. nestes ingredientes pode contaminar os alimentos para animais e podem desencadear doenças e ou torná-los portadores e veículos potenciais de contaminação humana. A temperatura de processamento das farinhas é alta o suficiente para eliminar a Salmonella spp. na matéria-prima, por isso a contaminação cruzada pósprocessamento deve ser monitorada e controlada. Este estudo teve o objetivo de avaliar a correlação entre presença pragas e provas positivas de Salmonella em fábricas de farinha de peixe. Os resultados encontrados apontaram uma correlação positiva entre estas variáveis. Porém a interação entre estes fatores é influenciada diretamente pelo programa de boas práticas de fabricação, particularmente nos requisitos de controle de pragas, definição de uma política de gestão de crises para tomada de decisões de forma rápida e eficiente quando do surgimento de problemas e, finalmente, a definição de uma política de gestão estratégica visando anteceder-se às oscilações de mercado.
\end{abstract}

Palavras-chave: Salmonella. Farinha de peixe. Controle de pragas.

1 Trabalho de Conclusão de Curso do MBA em Gestão para Segurança de Alimentos, SENAIsc. 


\section{INTRODUÇÃO}

Segundo a Organização Mundial de Saúde (OMS), zoonoses são "doenças ou infecções naturalmente transmissíveis entre animais vertebrados e seres humanos". Mais de 200 doenças enquadram-se nesta definição, classificadas didaticamente segundo o sentido de direção (antropozoonoses, zooantropozoonoses e amphixenosis), ciclo de manutenção do agente (diretas, ciclozoonoses - euzooneoses e parazoonoses, metazoonoses, saprozoonoses) e principal elo da cadeia de transmissão (mantidas por animais de companhia, transmitidas por alimentos de origem animal e cujos ninhos naturais são animais selvagens) (WHO, 2008).

Entre as principais zoonoses de origem bacteriana, destacam-se as salmoneloses, causadas por Salmonella spp., um dos agentes patogênicos mais frequentes em surtos de doenças transmitidas por alimentos (DTA) em humanos (ROSSI, 2005; WHO, 2008). As salmoneloses estão relacionadas principalmente ao aumento da escala industrial de processamento de alimentos, aumento do número de restaurantes fast food e mudanças nos hábitos alimentares. Entretanto, outros meios, como o cultivo e o contato com animais de abate, animais de estimação domésticos ou exóticos e a existências de organismos resistentes pelo uso excessivo de antibióticos humanos ou veterinários também são responsabilizados (BLANCOU et al., 2005).

Animais de abate contaminam-se de forma direta ou cruzada, podendo dentre outras formas contaminar-se no ambiente de criação através de ingestão de alimentos contaminados (STÄRK et al., 2002). A Salmonella pode contaminar os alimentos para animais de forma direta, através do uso de ingredientes contaminados, ou por contaminação cruzada durante o processo de fabricação e armazenamento, onde vetores, como baratas ou ratos, servem de veículo deste agente.

Ingredientes de origem animal, como a farinha de peixe, são importantes fontes de proteína em formulações de alimentos para animais de custo mínimo para avicultura, suinocultura, aquacultura e petfood. A presença de patógenos nestes ingredientes pode ser transferida aos alimentos para animais que, quando ingeridos pelas espécies alvo podem desencadear doenças e ou tornar estes animais portadores e veículos potenciais de contaminação humana através de sua carne, no caso de animais de produção, ou até mesmo pelo contato direto, no caso de animais de estimação.

A produção de farinha de peixe envolve um processo industrial composto de passos que vão do recolhimento de matéria-prima ao produto pronto, passando por cozimento, prensagem, moagem, resfriamento e, finalmente, embalagem. Diferentes fatores podem afetar a segurança da farinha como ingrediente para alimentos animais, especialmente relacionados à contaminação cruzada. A presença de Salmonella, além da patogenicidade, indica falhas de higiene. Tendo em vista que o processamento térmico da farinha a temperaturas acima de 110 ㄷ Ce suficiente para eliminar a Salmonella da matéria-prima, é necessário estabelecer métodos de controle dos mecanismos de contaminação pós- 
processamento, evitando a disseminação de patógenos na cadeia produtiva desde a produção de alimentos para animais até o homem.

Condições alheias ao quadro gerencial, como exemplo as oscilações de mercado, são capazes de provocar retenção de produto acabado além da capacidade de armazenagem, o que afeta a correta execução das boas práticas de fabricação. A escolha da estratégia de controle a ser aplicada nestas situações depende da interação entre os fatores coexistentes durante o processo, que ainda é pouco estudada e de alto grau de especificidade, justificando a elaboração deste trabalho.

\subsection{Objetivo Geral}

O objetivo deste trabalho foi avaliar a correlação entre presença de pragas, quantidade estocada e prevalência de Salmonella em fábrica de farinha de peixe.

\section{REFERENCIAL TEÓRICO}

\section{Salmonella}

O gênero Salmonella compreende bastonetes Gram negativos que pertencem à família Enterobacteriaceae. São anaeróbias facultativas, usualmente móveis com flagelos peritríquios, com exceção dos serovares $S$. Pullorum e $S$. Gallinarum que são imóveis. Salmonelas apresentam como condições ótimas de crescimento temperatura de $370 \mathrm{C}$, pH 7,0 e atividade de água mínima 0,94 (POPOFF e LE MINOR, 2005).

Mais de 2.500 sorotipos desta bactéria já foram identificados pelo Centro de Referência e Pesquisa em Salmonella do Instituto Pasteur (Paris), colaborador da Organização Mundial de Saúde (PATRICK e FRANÇOIS-XAVIER, 2007; WHO, 2005).

Os surtos de Salmonella em humanos geralmente estão relacionados ao consumo de alimentos de origem animal, especialmente carne de frango ou ovos. Nos últimos anos, porém, tem aumentado o relato de casos associados ao consumo de carne suína, bovina, leite, pescados, produtos de confeitaria recheados com cremes, gelatina desidratada, cacau, chocolate, côco, mariscos e molhos para saladas não industrializados. Vegetais contaminados com esterco também são relatados como alimentos envolvidos em casos de salmonelose (CASTAGNA et al., 2004; FDA/CFSAN, 2007).

As salmonelas são amplamente distribuídas na natureza, sendo o trato intestinal dos seres humanos e dos animais o principal habitat. Entre os animais, as aves (galinhas, perus, patos, gansos) podem ser portadoras assintomáticas e são consideradas o mais importante reservatório natural. Suínos, bovinos, equinos e animais silvestres (roedores, anfíbios e répteis) e animais domésticos (cães, gatos, pássaros, etc.) também podem ser portadores de salmonelas (GERMANO e GERMANO, 2003). Um grande número dessas bactérias é eliminado nas fezes, contaminando o solo e a água. 
A Salmonella é susceptível à maioria dos desinfetantes de uso em instalações industriais, como compostos fenólicos, iodados, iodóforos, formaldeído, hipoclorito de sódio $1 \%$, etanol $70 \%$, glutaraldeído $2 \%$. Pode também ser destruída pelo calor seco (160-170ㄷ/1h) e calor úmido (121으/15min) (OIE/CFSPH, 2005).

A presença de salmonelas indica falhas de higiene, sendo algumas espécies capazes de sobreviver por até mais de um ano em alimentos com baixa atividade de água (GERMANO e GERMANO, 2003), como os alimentos para animais.

\subsection{Alimentos para animais como contaminante}

Nos últimos anos, a preocupação pública a respeito da segurança de alimentos tem aumentado. A saúde dos animais destinados ao consumo humano e o risco da presença de contaminantes associados ao uso de alimentações comerciais para animais são aspectos questionados. Os principais contaminantes dos alimentos para animais englobam Salmonella, micotoxinas, resíduos de drogas veterinárias, poluentes orgânicos persistentes, agrotóxicos e outros produtos químicos (resíduos de solventes, melamina), metais pesados (mercúrio, chumbo, cádmio), excesso de sais minerais (cromo hexavalente, arsênico, selênio, flúor), e encefalopatias espongiformes transmissíveis (TACON E METIAN, 2008).

A redução ou a eliminação de patógenos de origem alimentar, como a Salmonella, na primeira fase da cadeia produtiva de alimentos (exploração agrícola) é importante para impedir a doença entre consumidores dos produtos de origem animal (MEERBURG e KIJLSTRA, 2007).

A Salmonella pode ser introduzida nos alimentos para animais de forma direta, através do uso de ingredientes contaminados, ou por contaminação cruzada durante o processo de fabricação e armazenamento. A pulverização de gordura animal ao final do processo, como realçador de sabor de alimentos para animais, também pode ser fonte de contaminação (FERRARO et al., 2008).

As principais fontes de contaminação de Salmonella envolvem as matérias-primas de origem animal, embora também possa ocorrer em matéria-prima de origem vegetal (Tabela 1). 
Tabela 1 - Prevalência de salmonelas em ingredientes, rações e swabs de pó colhidos em uma indústria de alimentos para animais

\begin{tabular}{|c|c|c|}
\hline \multicolumn{3}{|c|}{ Amostras cultivadas para salmonelas } \\
\hline Material amostrado & $\begin{array}{l}\text { Amostras positivas/amostras } \\
\text { examinadas }\end{array}$ & Percentual de amostras positivas \\
\hline Farinha de ossos & $8 / 13$ & 61,53 \\
\hline Farinha de peixe & $4 / 7$ & 57,14 \\
\hline Farinha de carne & $3 / 6$ & 50 \\
\hline Farinha de sangue & $1 / 3$ & 33,33 \\
\hline Farinha de ostra & $0 / 3$ & 0 \\
\hline Base seca de soro de queijo & $2 / 10$ & 20 \\
\hline Soro de leite & $1 / 18$ & 5,55 \\
\hline Leite em pó & $0 / 12$ & 0 \\
\hline Farelo de soja & $5 / 39$ & 12,82 \\
\hline Farelo de bolacha & $1 / 5$ & 20 \\
\hline Soja tostada & $1 / 7$ & 14,28 \\
\hline Farinha de trigo & $1 / 2$ & 50 \\
\hline Milho pré-gelatinizado & $0 / 8$ & 0 \\
\hline Milho moído & $0 / 3$ & 0 \\
\hline Rações prontas & $2 / 43$ & 4,65 \\
\hline Swabs de pó & $0 / 110$ & 0 \\
\hline & Fonte: Albuquerque, Ito e Miyaji (2 & 00) \\
\hline
\end{tabular}

As farinhas de origem animal (FOA) são matérias-primas amplamente utilizadas na indústria de alimentação animal devido ao seu alto valor nutricional, disponibilidade no mercado e custo. Estão relacionadas à grande parte dos casos de contaminação por ser um ótimo meio de crescimento para Salmonella.

A temperatura do processamento da farinha animal elimina grande parte, senão toda a contaminação bacteriana dos subprodutos. Entretanto, a recontaminação pósprocessamento é bastante incidente devido ao manuseio, transporte e outros fatores do ambiente e, por isso, deve ser monitorada periodicamente (BELLAVER, 2001). Conforme se observa na Tabela 1, as FOA podem ser consideradas as principais fontes de contaminação direta de alimentos para animais. Medidas defensivas para a contaminação por Salmonella nas plantas de FOA vêm sendo aplicadas incluindo limpeza, desinfecção e prevenção da condensação. Entretanto, a Salmonella não é controlada completamente somente com estas medidas e é necessário esclarecer os mecanismos da contaminação não somente dentro do processo de manufatura, mas igualmente durante todo o ambiente de fabricação (MORITA et al., 2006).

Subproduto do abate do pescado, rico em proteína, a farinha de peixe é matéria-prima de alto valor nutricional empregada em formulações de dietas para diferentes animais de interesse zootécnico. Seu processo de produção é composto basicamente das seguintes etapas: recepção de matéria prima, cozimento, extração de gordura, moagem, ensaque. 
Há informações limitadas sobre o risco de contaminação cruzada por Salmonella da alimentação animal, dos ingredientes e das fábricas a outras partes do ambiente, incluindo animais selvagens, e sobre o risco a saúde da possível exposição dos operários a alimentação contaminada por Salmonella ou a seus ingredientes (LUNESTAD et al., 2007).

Porém falhas nas boas práticas de fabricação podem, em tese, facilitar o contato da Salmonella com produto acabado através de sua veiculação por operadores, utensílios contaminados e vetores, como ratos, baratas e pássaros (DAVIES e WRAY, 1997 apud LUNESTAD et al., 2007).

\subsection{Contaminação por pragas}

Roedores constituem um sério risco à saúde humana, sendo vetores de doenças infecciosas como hantavirose, leptospirose, tulariose, febre de Haverhill, e salmoneloses (FAULDE, 2004). Frequentemente associados somente às perdas econômicas envolvendo danos estruturais e aos produtos armazenados, podem aumentar o número de patógenos no ambiente e transferi-los aos animais e aos alimentos dos animais, que podem contaminar direta ou indiretamente o homem. (MEERBURG e KIJLSTRA, 2007). Os ratos mais comum que colonizam e frequentam o ambiente de indústrias são o Mus musculo, Rattus novergicus e Rattus rattus, que são portadores de Salmonella Typhimurium, uma das espécies mais isoladas em humanos e produtos de origem suína ( $\mathrm{KICH}$ et al., 2005). Insetos e roedores residentes em fábricas de alimentos para animais Salmonella positivas tem mostrado carregar os mesmos serovares das salmonelas encontradas nas fábricas (DAVIES e WRAY, 1997 apud LUNESTAD et al., 2007). Hilton, Willis e Hickie (2002) recuperaram Salmonella de fezes secas de ratos marrons (Ratus norvegicus) por até 86 dias em cultura direta em meio ágar de desoxicolato-lisina-xilose (XLD), longevidade suficiente para apresentar um risco potencial da contaminação mesmo na ausência de uma infestação ativa.

Além das práticas de higiene já estabelecidas, o controle de roedores e outras pragas, como moscas e pássaros é necessário para a segurança dos alimentos (MEERBURG e KIJLSTRA, 2007). Kich et al. (2005) observaram soroprevalência de $78 \%$ de Salmonella em granjas que não controlavam roedores.

Morita et al. (2006) estabeleceram métodos de controle específicos da Salmonella para plantas de óleo vegetal, investigando vetores de contaminação, fatores ambientais e eficácia do uso de desinfetantes. As taxas elevadas da contaminação por Salmonella no piso de processamento representam um grande risco de contaminação do óleo através dos operadores, da poeira no ar e dos roedores. Dos roedores capturados, alto índice de portadores foram encontrados nas áreas de elevada contaminação, condizendo com Henzeler (1992) apud Morita (2006), que sugere que a taxa de portadores entre os roedores é proporcional ao nível de contaminação no ambiente de que foram capturados. Através de análise de eletroforese de gel em campo pulsado (PFGE) detectouse que estes isolados têm a mesma origem dos demais isolados distribuídos por toda 
a planta, confirmando que houve contaminação cruzada. As botas e vassouras foram consideradas importantes na propagação da Salmonella, principalmente nas áreas onde o piso contém muito óleo, capaz de aumentar a aderência deste patógeno. Além disso, sugere-se que a poeira do ar está envolvida na contaminação do óleo vegetal durante o processo de manufatura, confirmando o que Tuompo et al. (1999) apud Morita et al. (2006) relataram como uma fonte importante de contaminação por Salmonella em plantas da alimentação animal. A limpeza e desinfecção frequente e eficaz do piso de processamento, a restrição do movimento de operadores e ferramentas de trabalho e a exterminação periódica dos roedores são os meios recomendados para reduzir a taxa da contaminação por Salmonella.

\section{PROCEDIMENTOS METODOLÓGICOS}

Foi avaliada a correlação entre quantidade de farinha de peixe estocada, presença de roedores e resultado de provas positivas para diagnóstico de Salmonella.

\subsection{Local da pesquisa}

A pesquisa foi realizada em uma unidade de estocagem de uma fábrica de farinha de peixe de porte médio do litoral de Santa Catarina - Brasil, ao longo de 48 meses entre os anos de 2005 e 2008. A empresa possui o programa de boas práticas de fabricação implementado de acordo com a Instrução Normativa № 34, de 28 de maio de 2008 (BRASIL, 2008a) e sua planta é dividida em 3 áreas de acordo com a atividade: área de recepção do resíduo de pescado, área de processamento e área de armazenamento e expedição. Na área de recepção os veículos de transporte são inspecionados e a matériaprima é classificada e liberada ou devolvida, de acordo com os critérios estabelecidos pela empresa. A matéria-prima é transportada com auxílio de uma mão hidráulica e caracóis de aço até a área de processamento onde é cozida por batelada em digestores por um tempo médio de 2 horas e 30 minutos a uma temperatura média de $121^{\circ} \mathrm{C}$, que garante a descontaminação completa do produto. Após o cozimento são realizadas a descarga dos digestores e a prensagem, para remoção do excesso de gordura. Em seguida a farinha é moída, resfriada e ensacada. No silo de ensaque recebe a adição de anti-salmonela (Sal Zap Plus - Alltech), aditivo a base de ácidos orgânicos e formaldeído, que atua como bactericida, sendo mais uma garantia de inocuidade. A área de armazenamento é composta por galpões pré-moldados anexos a área de processamento, sem, no entanto, ter contato direto com esta. $O$ piso é de concreto e o ambiente da fábrica é geralmente empoeirado dado à natureza pulverulenta do produto final. Os equipamentos de cozimento e prensagem não são conectados, exigindo a manipulação entre estas etapas. Os operadores da área de recepção da matéria-prima (área suja) não se comunicam com a área de processamento e armazenamento (área limpa).

Para este estudo, foi considerado apenas um galpão de armazenamento $\left(800 \mathrm{~m}^{2} \mathrm{e}\right.$ capacidade de estocagem de 450 toneladas) que teve produto estocado por um longo período em função de condições adversas de mercado. 


\subsection{Capacidade de estocagem}

Mensalmente foi realizada a contagem do estoque existente ao final do mês e ajustado com relação ao valor máximo de estocagem de $100 \%$ (1), considerando as condições ideais de armazenamento que permitiam a circulação de pessoas, equipamentos, distância mínima do chão $(20 \mathrm{~cm})$ e de paredes $(30 \mathrm{~cm})$.

\subsection{Consumo de iscas raticidas}

Iscas raticidas foram dispostas em 80 porta-iscas em torno da empresa, mapeadas conforme croqui de monitoramento do Procedimento Operacional Padronizado (POP) de controle de pragas. O controle das iscas foi quinzenal, gerando 96 planilhas de consumo ao longo do experimento. A média de consumo mensal foi ajustada para um valor percentual, onde $100 \%$ de consumo equivale ao índice 1.

\subsection{Diagnóstico de Salmonella}

Foram coletadas aleatoriamente 6 amostras mensais de farinha de peixe, totalizando 288 amostras, as quais foram submetidas a análise bacteriológica em laboratório terceirizado para identificação de presença ou ausência de Salmonella em 25 g de amostra. Os casos positivos foram comparados com total de amostras enviadas e determinado o valor onde 1 equivale a $100 \%$.

\subsection{Análise estatística dos dados}

As informações obtidas foram submetidas à análise de correlação $(P>5 \%$ ou 0,05$)$ e foram determinados os coeficientes de Pearson através do software Minitab 12.0.

\section{RESULTADOS E DISCUSSÃO}

A Figura 1 mostra a evolução das variáveis de monitoramento ao longo do período estudado. 


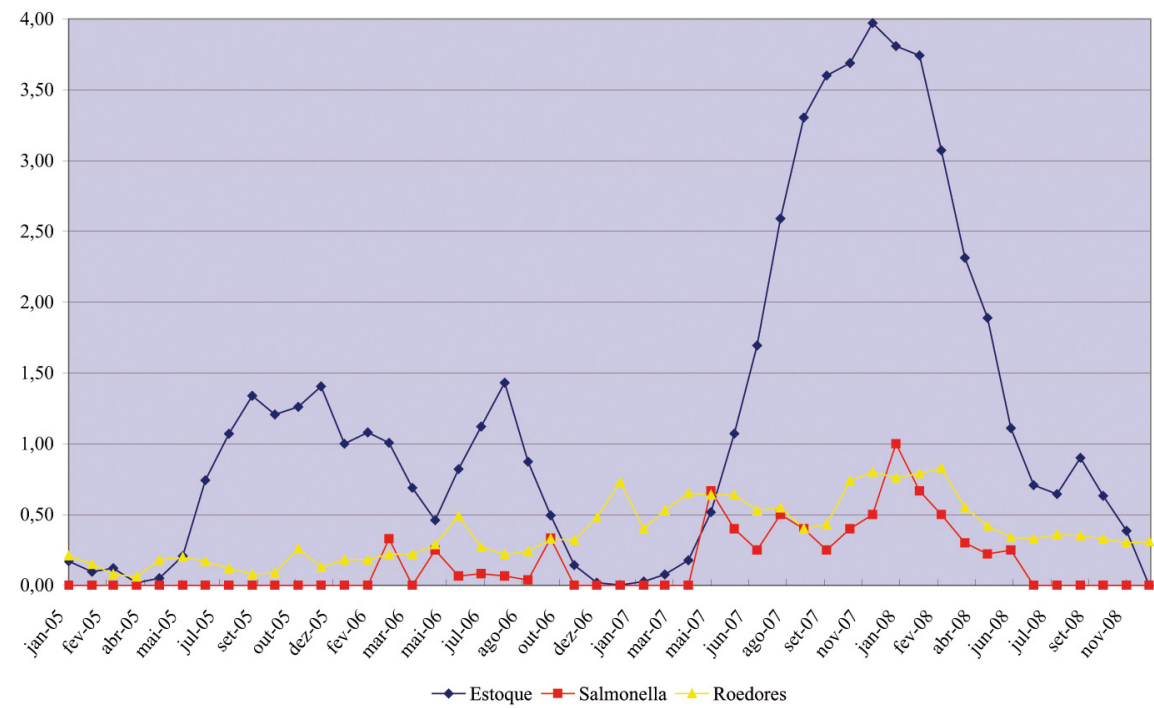

Figura 1 - Comportamento do volume de farinha de peixe estocada, pesquisa de Salmonella e presença de roedores entre janeiro de 2005 e dezembro de 2008

\begin{tabular}{|l|l|l|l|}
\hline \multicolumn{1}{|l|}{$\begin{array}{l}\text { Provas de } \\
\text { Salmonella }\end{array}$} & $\begin{array}{l}\text { Volume } \\
\text { Estocado } \\
\text { Pearson }\end{array}$ & $\begin{array}{l}\text { Provas de } \\
\text { Salmonella }\end{array}$ \\
\hline $\begin{array}{l}\text { Consumo de } \\
\text { iscas raticidas }\end{array}$ & $\begin{array}{l}\text { Valor de } P \\
\text { Coeficiente de } \\
\text { Pearson }\end{array}$ & 0,730 & 0,0001 \\
& Valor de $P$ & 0,0001 & 0,691 \\
\hline
\end{tabular}

Quadro 1 - Correlação entre provas positivas para Salmonella, volume estocado e consumo de iscas raticidas avaliado pelo coeficiente de correlação linear de Pearson

No Quadro 1, os coeficientes de Pearson próximos de 1 demonstram uma correlação linear positiva entre as variáveis acompanhadas.

A relação entre o aumento no número de pragas e a possibilidade de contaminação cruzada já é conhecida, porém em situação práticas do dia-a-dia de uma empresa o controle destas variáveis nem sempre é simples por envolver condições alheias à vontade do proprietário e encarregados da manutenção e garantia da qualidade.

Analisando particularmente o caso que foi objeto deste estudo, percebe-se que a sazonalidade do processo produtivo da farinha de peixe é condicionada pela pesca. 
Já o consumo envolve diferentes variáveis, como preço e disponibilidade de outras fontes de proteína de origem animal e necessidade de ajuste de custo de formulações. A substituição de farinha de peixe por outros ingredientes provoca uma migração do mercado consumidor, constituído basicamente de fábricas de alimentos para animais. A demanda, neste caso, é definida pelo setor de produção primária, principalmente aquacultura, e pela demanda internacional por farinha de peixe.

A fábrica de farinha possui compromisso com o recolhimento do subproduto da indústria pesqueira. Logo, não pode simplesmente deixar de receber matéria-prima, independente da demanda pela farinha. Assim, grandes oscilações no nível de estocagem acontecem invariavelmente. Um volume muito grande de estocagem, no entanto, interfere na organização do depósito, princípio básico para manutenção das boas práticas de fabricação.

O armazém de estocagem possui uma capacidade de carga determinada em função do histórico de mercado e de condições normais de armazenamento, número de linhas de paletes, empilhamento máximo e distância da parede e do chão, o que permite além do controle de entrada e saída de lotes seguindo o esquema PEPS (primeiro que entra, primeiro que sai), condições para circulação, higiene do ambiente e visualização de indícios de pragas.

Em função da diminuição na demanda por farinha ocorrida ao longo de 2007, o volume armazenado aumentou muito, obrigando a empresa a aumentar a quantidade de paletes nas pilhas e otimizar a área útil do depósito, o que além de diminuir a área de circulação e higienização teve sua condição agravada pelo desabamento de uma pilha que exerceu efeito dominó sobre as outras, dificultando ainda mais a manutenção das boas práticas de fabricação, principalmente no que diz respeito ao controle da nidificação de roedores no interior do referido depósito.

A Figura 1 mostra que entre julho de 2005 e fevereiro de 2006, mesmo ocorrendo aumento no volume estocado até o máximo de 1,41 vezes a capacidade de estoque esta não provocou aumento representativo nos casos de Salmonella, pois o aumento do estoque não foi acompanhado do aumento na população de pragas, que são os vetores deste patógeno.

Entre os meses de junho de 2007 e junho de 2008, no entanto, o volume de produto estocado ultrapassou a capacidade de estocagem em 1,5 vezes, acompanhado de aumento na população de roedores, o que aumentou a incidência de resultados positivos para Salmonella nas amostras encaminhadas para análise.

Em novembro de 2007, o mercado de farinha de peixe voltou a ficar aquecido, com aumento na demanda, propiciando maior comercialização ao longo de todo ano de 2008. À medida que o volume de produto estocado diminuiu, foi possível reestabelecer completamente o controle de pragas, pois até mesmo o tráfego de pessoas era impossível de realizar-se com estoque acima de 1,5 da capacidade de estocagem. 
Contribuíram para interação entre os fatores:

a) Falta de uma política clara para a gestão de crises que permitisse tomada de decisões imediatas quando do surgimento dos primeiros problemas;

b) Inexistência de um programa de gestão estratégica que permita conciliar oferta e demanda de forma a diminuir a sazonalidade dos estoques, prever condições futuras de aumento de produção e antecipar as condições adequadas ao armazenamento;

c) Falta de cumprimento do Programa dos 5 Sensos (5 S), principalmente do senso de organização;

d) Falta de cumprimento das premissas básicas de boas práticas de fabricação, que prevê disposição de produto armazenado com distância mínima de pisos e paredes que permita a fácil higienização e trânsito de pessoas;

e) E finalmente, monitoramento inadequado do POP de controle integrado de pragas, para se antecipar ao aumento na população de roedores.

\section{CONCLUSÃO}

Considerando os dados acima, conclui-se que existe uma correlação direta entre a presença de pragas, avaliada pelo aumento no consumo de iscas raticidas, aumento nos estoques e incidência de Salmonella em farinha de peixe.

Contribuíram para este quadro as condições de mercado, que levaram a diminuição na demanda e retenção da produção com consequente aumento do estoque que, somado ao armazenamento inadequado por falta de espaço e organização, permitiram a nidificação de roedores, veículo de contaminação cruzada com Salmonella.

Apesar das condicionantes de mercado que regulam a oferta e a demanda não terem a interferência voluntária da empresa, a definição de uma política para a gestão de crises que permita a tomada de decisões imediatas, quando do surgimento dos primeiros problemas, associada a um programa de gestão estratégica capaz de conciliar oferta e demanda e antecipar as condições de armazenagem adequadas ao aumento do estoque, são medidas importantes para a manutenção da ordem necessária para a segurança do processo. 


\title{
EVALUATION OF THE CORRELATION BETWEEN THE PRESENCE OF PLAGUES AND PREVELENCE OF SALMONELLA IN A FISHMEAL COMPANY
}

\begin{abstract}
Ingredients of animal origin such as fishmeal, are important sources of protein for animal feed. The presence of zoonotic pathogens such as Salmonella spp. in these ingredients can contaminate food and can trigger diseases in animals and patients or make them potential vehicles of human contamination. The processing temperature of the flour is high enough to eliminate Salmonella spp. in the raw material, so the postprocessing cross-contamination should be monitored and controlled. This study aimed to evaluate the correlation between the presence of pests and positive prevalence of Salmonella in fish meal factories. The results showed a positive correlation between these variables. But the interaction between these factors is influenced directly by the program of good manufacturing practices, particularly in pest control requirements, definition of a political crisis management to make decisions quickly and effectively when problems occur, and finally the formulation of a strategic management in order to proceed to market fluctuations.
\end{abstract}

Key-words: Salmonella. Fishmeal. Pest control.

\section{REFERÊNCIAS}

ALBUQUERQUE, R.; ITO, N.M.K.; MIYAJI, C.I. estudo da ocorrência de salmonelas em ingredientes, rações e suabes de pó colhidos em uma fábrica industrial de ração.

Brazilian Journal of Veterinary Research and Animal Science, São Paulo, v. 36, n. 6, 1999. Disponível em: < http://www.scielo.br/scielo.php?script=sci_arttext\&pid =S1413-95961999000600008>. Acesso em 15 de dezembro de 2008.

BELLAVER, C. Processamento e cuidados com produtos de origem animal: higiene e profilaxia. In: SIMPÓSIO SOBRE MANEJO E NUTRIÇÃO DE AVES E SUÍNOS E TECNOLOGIA DA PRODUÇÃO DE RAÇÕES, 1, 2001, Campinas. Anais... Campinas: CBNA, 2001. 14p. Disponível em: < http://apps.fiesp.com.br/sbsnetv2/big/sindicato/ sindnaccoletoresbenefsubprodutosorigemanimal/downloads/notas/cbna_farinhas_ nov.pdf >. Acesso em: 10 de janeiro de 2008.

BLANCOU, J. et al. Emerging or re-emerging bacterial zoonoses: factors of emergence, surveillance and control. Veterinary Research, v. 36, p.507-522, 2005. Disponível em: $<$ http://www.vetres.org/index.php?option=article\&access=standard\&/temid=129\&u $\mathrm{rl}=/$ articles/vetres/pdf/2005/03/v4061.pdf>. Acesso em: 15 de dezembro de 2008. 
BRASIL. Ministério da Agricultura, Pecuária e Abastecimento. Instrução Normativa № 34, de 28 de maio de 2008, aprova o Regulamento Técnico da Inspeção HigiênicoSanitária e Tecnológica do Processamento de Resíduos de Animais e o Modelo de Documento de Transporte de Resíduos Animais. 2008a.

CASTAGNA, S.M.F. et al. Presença de Salmonella sp. no trato intestinal e em tonsilas/ linfonodos submandibulares de suínos ao abate. Arq. Bras. Med. Vet. Zootec, v. 56, n. 3, p. 300-306, 2004. Disponível em: <www.scielo.br/pdf/abmvz/v56n3/v56n3a03.pdf >. Acesso em: 10 de janeiro de 2009.

FAULDE, M. K. Rats and mice - Neglected vectors and reservoirs of dangerous infectious diseases? Hygiene + Medizin, v. 29, n. 6, p. 206-216, jun. 2004. Abstract. Disponível em: <http://www.scopus.com/scopus/source/sourcelnfo.url?sourceld=65029>. Acesso em: 18 de dezembro de 2008.

FDA/CFSAN - United States Food and Drug Administration. Center for Food Safety and Applied Nutrition. Foodborne Pathogenic Microorganisms and Natural Toxins Handbook "Bad Bug Book". Maryland: FDA, 2007. Disponível em: <http://www.cfsan. fda.gov/ mow/ chap1.html> Acesso em: 2 de janeiro de 2009.

FERRARO, A. et al. Multistate outbreak of humam Salmonella infections caused by contaminated dry dog food - United States, 2006-2007. Morbidity and Mortality Weekly Report, v. 57, n. 19, p. 521-524, 2008. Disponível em: <http://www.cdc.gov/ $\mathrm{mmwr} / \mathrm{preview} / \mathrm{mmwrhtml} / \mathrm{mm} 5719 \mathrm{a} 4 . \mathrm{htm}>$. Acesso em: 3 de fevereiro de 2009.

GERMANO, P.M.L.; GERMANO, M.I.S. Higiene e vigilância sanitária de alimentos: qualidade das matérias-primas; doenças transmitidas por alimentos; treinamento de recursos humanos. 2. ed. rev. e ampl. São Paulo: Varela, 2003. 655p.

HILTON, A.C.; WILLIS, R.J.; HICKIE, S.J. Isolation of Salmonella from urban wild brown rats (Rattus norvegicus) in the West Midlands, UK. International Journal pf Environmental Health Reserach, v.12, n.2, p.163-168. jun. 2002. Abstract. Disponível em: <http://informaworld.com/smpp/content=a713671392 tab=content $>$. Acesso em: 15 de dezembro de 2008.

$\mathrm{KICH}$, J.D. et al. Fatores associados à soroprevalência de Salmonella em rebanhos comerciais de suínos. Ciência Rural, Santa Maria, v. 35, n. 2, p. 398-405, mar./abr. 2005. Disponível em: <www.scielo.br/pdf/cr/v35n2/a24v35n2.pdf >. Acesso em: 10 de janeiro de 2009.

LUNESTAD, B.T. Salmonella in fish feed; occurence and implications for fish and human health in Norway. Aquaculture, Amsterdam, v. 265, n. 1-4 , p. 1-8, 2007. Disponível em: <www.sciencedirect.com>. Acesso em: 15 de dezembro de 2008. 
MORITA, T. et al. Prevention of Salmonella cross-contamination in an oilmeal manufacturing plant. Journal of Applied Microbiology, v. 101, n. 2 , p. 464-473, ago. 2006. Disponível em: <www.interscience.wiley.com/cgi-bin/fulltext/118566858/ PDFSTART>. Acesso em: 15 de fevereiro de 2009.

OIE/CFSPH - Office International des Epizooties. Center for Food Security and Public Health. Salmonellosis: paratyphoid, non-typhoidal salmonellosis. Ames: lowa State University, College of Veterinary Medicine, 2005. 8p. Disponível em: http://www.cfsph. iastate.edu/Factsheets/pdfs/Nontyphoidal_Salmonellosis.pdf. Acesso em 5 fev 2009.

PATRICK, G.; FRANÇOIS-XAVIER, Weill. Rapport d'activité annuel 2007. Paris: Institut Pasteur, Centre Nacional de Référence des Salmonella, 2007. Disponível em: < http:// www.pasteur.fr/sante/clre/cadrecnr/salmcnr/web-CNR-Salm2007.pdf>. Acesso em: 2 de fevereiro de 2009.

POPOFF, M.Y.; LE MINOR, L.E.. Genus XXXIII Samonella. In: Brenner, D.J., Krieg, N.R.; Staley, J.T. (Eds) Bergey's Manual of Systematic Bacteriology. 2. ed. New York: Springer Science+Business Media Inc., 2005. v. 2, p. 764-799.

ROSSI, A.A. Biossegurança em frangos de corte e saúde pública: limitações, alternativas e subsídios na prevenção de salmoneloses. 2005. 111f. Dissertação (Mestrado em Agroecossistemas) - Centro de Ciências Agrárias, Universidade Federal de Santa Cataria, Florianópolis, 2005.

STÄRK, K.D.C. et al. Differences and similarities among expert's opinions on Salmonella enteric dynamics in swine pre-harvest. Preventive Veterinary Medicine, v. 53 , n. 1-2, p. 7-20, fev. 2002. Disponível em: <www.sciencedirect.com >. Acesso em: 18 de dezembro de 2008.

TACON, A.G.J.; METIAN, M. Aquaculture feed and food safety: The role of the food and agriculture organization and the codex alimentarius. Annals of the New York Academy of Sciences, v. 1140, p. 50-59, out. 2008. Abstract. Disponível em: <http://scopus.com/ scopus/source/sourcelnfo.url?sourceld=21754>. Acesso em: 15 de dezembro de 2008. Abstract.

WHO - World Health Organization. Drug-resistant Salmonella. Fact Sheet №139, Revised April, 2005. Disponível em: <http://www.who.int/mediacentre/factsheets/ fs139/en/>. Acesso em 30 de dezembro de 2008.

WHO - World Health Organization. Zoonoses and veterinary public health (VPH). 2008. Disponível em: <http://www.who.int/zoonoses/en/>. Acesso em 30 de dezembro de 2008. 


\section{SOBRE OS AUTORES}

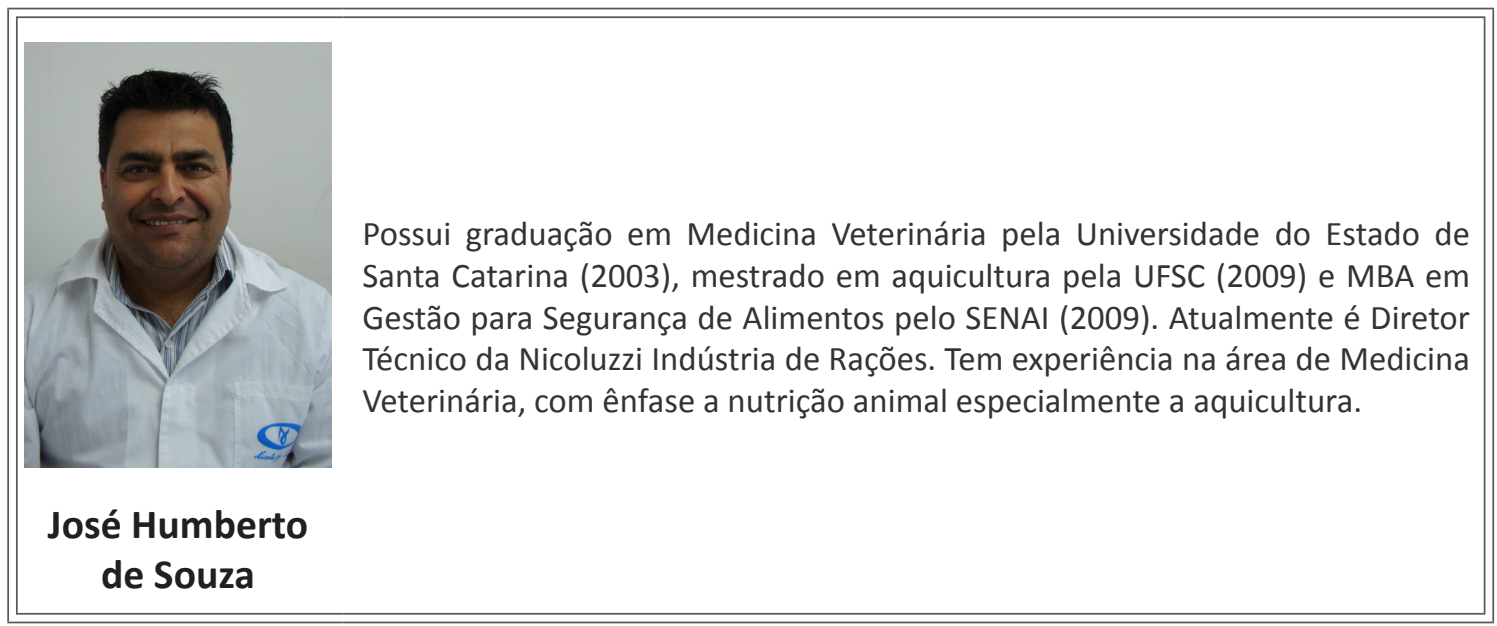

\begin{tabular}{|l} 
Médica Veterinária graduada pela Universidade Federal de Uberlândia (UFU) \\
e mestra em Ciência de Alimentos pela Universidad Autonoma de Barcelona \\
(UAB), Espanha. \\
É Lead Assessor na ISO 9001, consultora e multiplicadora do Programa Alimentos \\
Seguros (PAS) - Setor Indústria. \\
Atuou como instrutora e consultora do SENAI SC em Florianópolis para \\
implantação de Sistemas de Gestão para a Segurança de Alimentos. Foi \\
coordenadora e docente do curso de Pós-Graduação MBA em Gestão para \\
Segurança de Alimentos a distância e trabalhou na implementação e em \\
auditorias internas de Sistemas de Gestão de Qualidade e de Segurança de \\
Alimentos em diversas indústrias da área. Autora do livro Sistemas de Gestão de \\
Segurança de Alimentos, em 2008, publicado pelo SENAl e do livro Sistema de \\
Qualidade em Segurança de Alimentos: ABNT NBR ISO 22000:2006, Eurepgap \\
e BRC, publicado em 2007, pelo SENAI. Foi consultora da Organização Pan- \\
Americana da Saúde (OPAS/ OMS) em 2000-2001. \\
Atualmente é Coordenadora da Rede SENAI/SC de Educação a Distância.
\end{tabular}

